relations between the decrease in the Stern layer capacity and the added amounts of surface active agents and dioxane. For such cases, the electrochemical free energy of adsorption must be used in order to obtain adequate distribution functions. The final equations thus obtained involve the surface potential and the surface charge as variables, and can be used to reproduce observed relations between the double layer capacity and the polarisation.

(Received Dec. 25, 1960)

\title{
Sintered-Type Alkaline Storage Batteries. VI. Influence of Preparing Conditions upon the Durability of the Sintered-Type Cadmium Negative Plate
}

\author{
Kuranobu Sugita
}

Railway Technical Research Institute, Kunitachi, Tokyo

\section{Purpose and Method of the Experiments}

Capacity of the sintered-type cadmium negative plate decreases gradually with the repeated charge and discharge cycles. In this experiment, influences of the preparing conditions, such as sorts of cadmium salts for impregnation, specific gravities, current densities for reduction and sintering temperatures of plaques on the durability of the negative plate were examined, because it was considered that they have some connection with the plate performance.

Preparation of the plate was made by the usual method except in the impregnation of the active material; it was done under atmospheric pressure in this experiment. The impregnation were repeated 5 to 7 times and the weights of active material were 11 to $13 \mathrm{~g}$.

One of the test plates and two of the pocket-type positive plates which had larger capacity than the negative plate were combined in a $500 \mathrm{cc}$ glass vat. These plates were separated by a glass rod and the vat was filled with $\mathrm{KOH}$ aqueous solution. (sp. gr. 1.24 at $20^{\circ} \mathrm{C}$ )

The test cells were set in an air-thermostat. Capacity and life tests were carried out after the initial charge. Conditions of the tests were as follows :

Capacity test; discharged at $0.5 \mathrm{~A}$ until the end voltage of $1.0 \mathrm{~V}$

Life test; discharged at about $1.4 \mathrm{~A}$ for $1 \mathrm{~h}$

charged at about $2.5 \mathrm{~A}$ for $1 \mathrm{~h}$

under constant resistance

temp., $30^{\circ} \pm 2^{\circ} \mathrm{C}$

\section{Results of the Experiments}

2.1 Effect of the sorts of cadmium salt and the current densities for reduction $\left.\mathrm{Cd}_{(\mathrm{NO}}\right)_{2}$ aq. and $\mathrm{CdCl}_{2}$ aq., (sp. gr. 1.50 at $20^{\circ} \mathrm{C}$ ) were used as the cadmium salts. The current densities for reduction were 4 and $10 \mathrm{~A} / \mathrm{dm}^{2}$. The preparations of plates and the life tests were both repeated twice, because there were often variances among the results of the experiments. The results on the capacity changes of the test plates are shown in Fig. 1 (the 1st experiments) and Fig. 2 (the 2nd experiments). On the plates prepared with $\mathrm{Cd}\left(\mathrm{NO}_{3}\right)_{2}$, the initial capacities are larger but the capacity decreases more than those with $\mathrm{CdCl}_{2}$.

On the effect of the current densities, decreases in the capacity of the plates reduced at $4 \mathrm{~A} / \mathrm{dm}^{2}$ are smaller than those reduced at $10 \mathrm{~A} / \mathrm{dm}^{2}$, as shown in Fig. 1, but they are not apparent in Fig. 2 . 


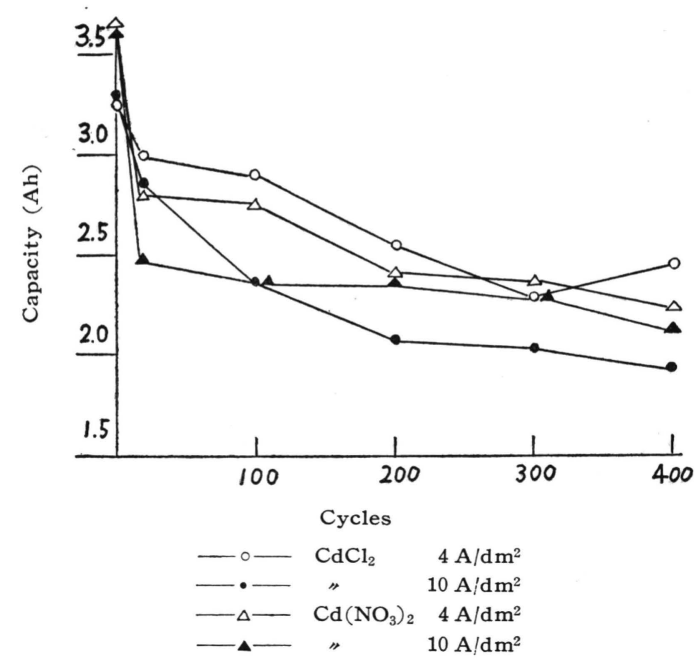

Fig. 1 Influence of the sorts of Cadmium salts and the current densities for reduction (the 1st exp.)

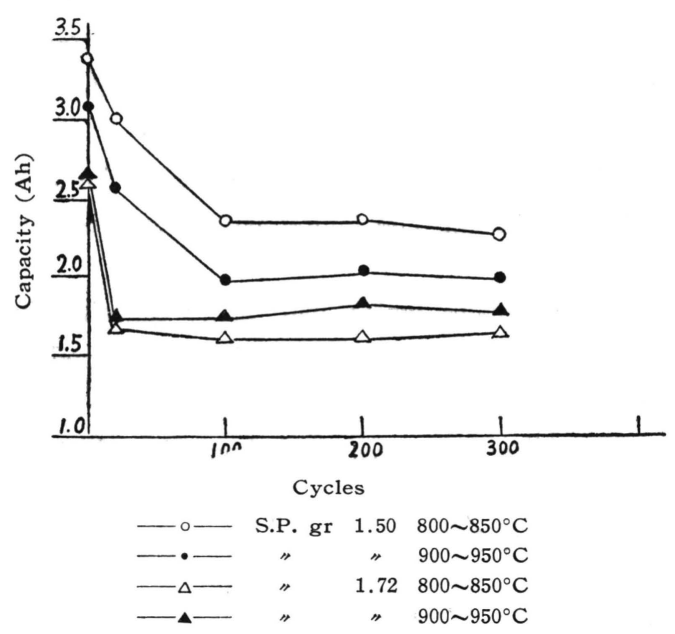

Fig. 3 Influence of the specific gravities of $\mathrm{CdCl}_{2}$ aq. and the sintering temperatures of the plaques

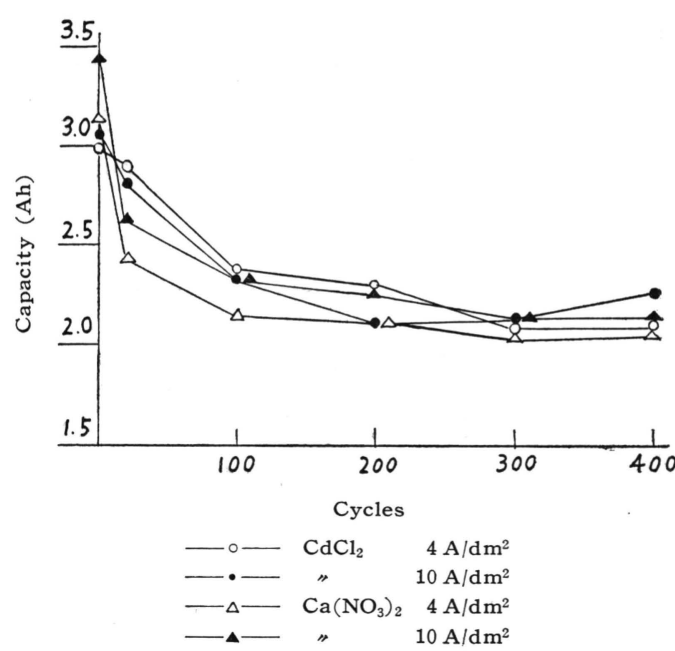

Fig. 2 Influence of the sorts of Cadmium salts and the current densities for reduction (the 2nd exp.)

\subsection{Effect of the specific gravities of} $\mathrm{CdCl}_{2}$ aq. and the sintering temperatures of the plaques The specific gravities of $\mathrm{CdCl}_{2}$ aq. were 1.50 and 1.72 at $20^{\circ} \mathrm{C}$ and the sintering temperatures were $800 \sim 850^{\circ} \mathrm{C}$ and 900 $\sim 950^{\circ} \mathrm{C}$. Two plates were prepared under each condition. Capacity and life tests were carried out and the mean value of the two were plotted in Fig. 3.

The plates prepared with $\mathrm{CdCl}_{2}$ aq. of sp. gr. 1.72 are smaller in the initial capacities and larger in the capacity decrease up to the 25 th cycle than those prepared with $\mathrm{CdCl}_{2}$ aq. of sp. gr. 1.50. The capacity changes between the 100 th and the 300th cycle are almost equal for the both.

The effect of sintering temperature on the capacities is not clear for the plates prepared

with $\mathrm{CdCl}_{2}$ aq. of sp. gr. 1.72. On the other hand, the capacity of the plate using the plaque sintered at low temperature is larger than that of the one using the plaque sintered at high temperature for the plate prepared with $\mathrm{CdCl}_{2}$ aq. of sp. gr. 1.50.

The best preparing conditions for the cadmium negative plate are as follows;

sintering temp., $800 \sim 850^{\circ} \mathrm{C}$

sintering time, $8 \mathrm{~min}$.

cadmium salt, $\mathrm{CdCl}_{2}$ aq., sp. gr. 1.50

(Received Mar. 22, 1961) 